\title{
DESEMPENHO DE BEZERROS DA RAÇA HOLANDESA SUPLEMENTADOS COM PROBIÓTICO A BASE DE SACCHAROMYCES CEREVISAE, CEPA KA500 E PEDIOCOCCUS ACIDILACTICI
}

\author{
André Thaler Neto ${ }^{1}$, Ivan Pedro de Oliveira Gomes ${ }^{1}$, André Luiz Garcia Dias ${ }^{1}$, Helder \\ de Arruda Córdova ${ }^{1}$, Jean Gabriel Dal Pizzol' ${ }^{1}$, Rafael Sachet Rodrigues ${ }^{1}$ \\ 1 UDESC \\ Correspondência: André Thaler Neto: thaler@cav.udesc.br
}

\begin{abstract}
RESUMO: O uso de probióticos em bezerros promove condições desfavoráveis para o crescimento de microrganismos patogênicos, podendo influenciar no desempenho dos animais. O presente trabalho teve por objetivo avaliar o efeito da suplementação com probiótico constituído de Saccharomyces cerevisiae cepa KA500 e Pediococcus acidilactici sobre o ganho de peso, consumo de alimentos, conversão alimentar e consistência fecal em bezerros da raça Holandesa. Foram utlizados 30 bezerros da raça Holandesa nas fases de aleitamento (1-6 semanas) e pós-aleitamento (7-12 semanas), sendo submetidos a dois tratamentos, onde 15 bezerros foram suplementados com probióticos ( $5 \mathrm{~g} /$ dia do $8^{\circ}$. dia de idade ao desaleitamento e $10 \mathrm{~g} / \mathrm{dia}$ a partir do desaleitamento) e 15 não suplementados (testemunha). O consumo de alimentos foi registrado diariamente, o peso vivo semanalmente e o escore de consistência fecal 3 vezes por semana. Observou-se superioridade no ganho de peso dos animais suplementados com probiótico, em relação aos animais não suplementados, sem alteração no consumo de concentrado, nos períodos de aleitamento e pósaleitamento, resultando em melhor conversão alimentar no período de aleitamento. Ocorreu diminuição no escore fecal dos bezerros suplementados durante o aleitamento, sem diferença significativa no período pós-aleitamento. Conclui-se que a suplementação com probióticos melhora o desempenho e a consistência fecal de bezerros nas primeiras 12 semanas de vida.
\end{abstract}

Palavras-chave: consistência fecal; conversão alimentar; ganho de peso; suplementação

\section{PERFORMANCE OF HOLSTEIN CALVES SUPPLEMENTED WITH PROBIOTIC CONSISTING OF SACCHAROMYCES CEREVISIAE, STRAIN KA500 AND PEDIOCOCCUS ACIDILACTICI}

\begin{abstract}
The use of probiotics in calves promote unfavorable conditions for the growth of pathogenic microrganisms, which may influence the performance of the animals. This study aims to evaluate the effect of supplementation of calves with probiotics consisting of Saccharomyces cerevisiae strain KA500 and Pediococcus acidilactici on weight gain, feed intake, feed conversion and fecal consistency of Holstein calves. In the experiment 30 Holstein calves, during the pre- (1 to 6 weeks) and post-weaning (7 to 12 weeks), were submitted to two treatments, with 15 calves supplemented with probiotics ( $5 \mathrm{~g} /$ day from 8 days of age to weaning and $10 \mathrm{~g}$ in the post-weaning) and 15 not supplemented (control). The feed intake were daily registered, the body weight weekly and the fecal score 3 times in the week. Increased body weight gain were observed in the supplemented compared to the not supplemented in pre- and post-weaned calves, without differences in the concentrate intake, resulting in better feed conversion in pre-weaned calves. There was a decrease in fecal score of pre-weaned calves. We are concluded that the supplementation with probiotics increase the performance and the fecal consistency of calves in the first 12 weeks.
\end{abstract}

Key Words: Fecal consistency; feed conversion; supplementation; weight gain 


\section{INTRODUÇÃO}

Um dos problemas da bovinocultura de leite é a ocorrência de diarreia em bezerros, causada pela proliferação de microrganismos indesejáveis que se alojam no trato gastrointestinal, impedindo a boa absorção dos nutrientes e comprometendo 0 desempenho (GONÇALVES et al., 2000), causando mortalidade e perdas econômicas (KAWAKAMI et al., 2010). Em propriedades leiteiras os bezerros são geralmente submetidos a estresses, mudanças alimentares e instalações sem condições sanitárias adequadas (TIMMERMAN et al., 2005), resultando em exposição a patógenos, elevando o risco do estabelecimento de uma microbiota indesejável que poderá desencadear diarreia e uso de antimicrobianos. Segundo Galvão et al. (2005), um método alternativo para melhorar o desempenho é fornecer aditivos alimentares não antimicrobianos que minimizem a colonização do trato digestivo por patógenos.

Fuller (1989) definiu o termo probiótico como um suplemento alimentar composto por microrganismos vivos que beneficiam a saúde do hospedeiro através do equilíbrio da microflora intestinal. Nos Estados Unidos foi adotado o termo direct-fed microbials (DFM), definido como uma fonte de microrganismos vivos de ocorrência natural no organismo animal (Krehbiel et al., 2003). No Brasil utilizase o termo probiótico, definido como cepas de microrganismos vivos e viáveis, que agem como auxiliares na recomposição da microbiota do trato digestivo dos animais, diminuindo o número de microrganismos patogênicos ou indesejáveis (MAPA, 2004). Os mecanismos de ação dos probióticos ainda não estão completamente esclarecidos (GARCIA, 2008), destacando-se $O$ efeito antagonista contra grupos específicos de organismos e a consequente exclusão competitiva por nutrientes ou sítios de ativação, a síntese de bacteriocinas que agem como antibióticos naturais, a prevenção da acidose ruminal e a ativação do sistema imune (FULLER, 1989), afetando a resposta inata, humoral e celular do sistema imunitário (KREHBIEL et al., 2003).

Os microrganismos usados como probióticos para ruminantes incluem culturas viáveis de fungos e bactérias. As bactérias ácido-láticas, grupo onde estão incluídos Lactobacillus, Leuconostic,

Streptococcus,

Lactococcus, Pediococcus (LJUNGH WADSTROM, 2006), constituem os principais componentes da proteção da microflora intestinal contra a colonização de microrganismos patogênicos (FILHO LIMA, 2000), sendo que espécies de Lactobacillus,

Enterococcus, Streptococcus e Bifidobacterium tem sido estudados em bezerros jovens (KREHBIEL et al., 2003). O Pediococcus acidilactici é um microrganismo natural de plantas utilizado em inoculantes de silagens, sendo identificado como uma bactéria com potencial de uso como probiótico em bovinos (RODRIGUEZ-PALACIOS et al., 2009).

As leveduras (Saccharomyces cerevisiae) ou fungos (Aspergillus oryzae) também têm sido amplamente utilizados na nutrição de ruminantes para melhorar o crescimento, produção e sanidade devido aos seus efeitos sobre a ingestão de matéria seca (IMS), $\mathrm{pH}$ do rúmen e digestibilidade (MARTIN e NISBET, 1992), sendo que os produtos solúveis presentes na cultura de leveduras têm mostrado inibir o crescimento e a atividade microbiana (JENSEN et al., 2008) e modular o sistema imunitário. Cultura de levedura contém células de levedura e compostos produzido durante a 
fermentação, tais como vitaminas do complexo B, polifenóis e ácidos orgânicos, os quais podem ser responsáveis pelos efeitos positivos sobre o desempenho e saúde, quando incorporados na dieta (MAGALHÂES et al., 2008).

Os probióticos podem ser usados como promotores de crescimento, constituindo-se em uma alternativa aos antibióticos (COPPOLA e TURNES, 2004), visto que a manutenção de microrganismos benéficos no intestino pode ajudar a suprimir os microrganismos patogênicos, reduzindo ou eliminando as diarreias (FULLER, 1989). Batista et al. (2008) relataram que a adição de probiótico ao leite sem resíduo de antibiótico é uma alternativa para reduzir os dias com diarreia em bezerras, sem influenciar o consumo e 0 ganho de peso dos animais. Pereira et al. (2008) relataram que em bezerros os probióticos podem promover condições desfavoráveis para o crescimento de microrganismos patogênicos, mantendo o equilíbrio da microbiota intestinal e ruminal, podendo influenciar no ganho de peso dos animais.

A resposta da utilização dos probióticos tem sido variada, dependendo da cepa, dose, duração da alimentação e tipo de tecidos e células analisadas (KREHBIEL et al., 2003). A influência da dose foi demonstrada por Lesmeister et al. (2004) em bezerros, onde a adição de $1 \%$ de culturas de leveduras no concentrado não afetou o desempenho, enquanto a inclusão de $2 \%$ melhorou a IMS, o ganho de peso e a eficiência alimentar. Alguns trabalhos também têm avaliado o efeito do uso de probióticos sobre a sanidade dos bezerros. Galvão et al. (2005) observaram redução no número de dias com diarreia e na necessidade de tratamento com antibióticos durante 0 aleitamento. Magalhães et al. (2008) não observaram diferença no escore fecal, porém redução na percentagem de bezerros tratados com antiinflamatórios e antidiarreicos e na taxas de sobrevivência aos 70 dias. Por outro lado, Gonçalves et al. (2000) e Pereira et al.(2008) não observaram efeito da utilização de probióticos sobre 0 desempenho de bezerros recebendo leite integral como dieta líquida até 60 e 90 dias de idade, respectivamente. Coletivamente, vários estudos tem demonstrados benefícios potenciais para a saúde dos animais, melhorando o desempenho.

O presente trabalho teve por objetivo avaliar 0 efeito da suplementação com probiótico a base de Saccharomyces cerevisae, cepa KA500 e Pediococcus acidilactici sobre o desempenho e a consistência fecal de bezerros da raça Holandesa.

\section{MATERIAL E MÉTODOS}

O trabalho foi desenvolvido em uma propriedade rural no município de Farroupilha - RS. Foram utilizados 30 bezerros machos da raça Holandesa, com peso inicial médio de $41,1 \mathrm{~kg}$, os quais receberam colostro e leite de transição até três dias de idade e água a vontade a partir do $4^{\circ}$ dia. Os animais foram alojados em bezerreiros com baias individuais, com piso de concreto e cama de maravalha. A partir do oitavo dia de vida os bezerros foram distribuídos aleatoriamente em dois tratamentos com 15 bezerros cada, suplementados e não suplementados com probióticos (controle). A duração do experimento foi de 12 semanas, considerando-se as fases de aleitamento (1-6 semanas) e pósaleitamento (7-12 semanas).

Do quarto ao sétimo dia de vida todos os bezerros receberam $5 \mathrm{~g}$ de um aditivo probiótico composto por cepas das bactérias Lactobacillus casei, $1 \mathrm{x}$ $10^{9} \mathrm{UFC} / \mathrm{g}$, e Bifidobacterium bifidum, 1 
x $10^{9} \mathrm{UFC} / \mathrm{g}$. A partir do oitavo dia de idade os animais foram suplementados ou não (controle) com um aditivo probiótico composto por Saccharomyces cerevisae, cepa KA500, 1 × $10^{10}$ leveduras vivas/grama, e Pediococcus acidilactici, cepa KA25, $5 \times 10^{8}$ células vivas/grama, na proporção de $5 \mathrm{~g} /$ dia até o desaleitamento e $10 \mathrm{~g} / \mathrm{dia}$ do desaleitamento ao final do período experimental. Inicialmente o probiótico era fornecido misturado ao leite e, assim que os bezerros passavam a se alimentar com concentrado, foi fornecido sobre o mesmo.

De 4 a 42 dias de vida todos os bezerros receberam diariamente $500 \mathrm{~g}$ de leite em pó diluído em dois litros de água, fornecido em duas vezes/dia. $\mathrm{O}$ desaleitamento ocorreu, de forma abrupta, no $42^{\circ}$ dia de vida. Após o desaleitamento os animais receberam água, concentrado à vontade e feno de azevém (Lollium multiflorum), na proporção de $20 \%$ do concentrado. A partir de 8 dias de idade todos os bezerros receberam concentrado inicial à base de milho, farelo de soja, casca de soja, sucedâneo lácteo como palatabilizante (4\%) e núcleo de minerais e vitaminas (4\%), contendo $20 \%$ de PB. A análise bromatológica dos alimentos utilizados encontra-se na Tabela1.

\begin{tabular}{lccc}
\hline \multicolumn{4}{l}{ Tabela 1 - Composição dos alimentos fornecidos aos bezerros (\% da MS). } \\
\hline & Leite em Pó & Concentrado & Feno \\
\hline Proteína Bruta & 26,61 & 21,94 & 9,56 \\
Extrato Etéreo & 27,58 & 3,10 & 1,41 \\
FDN & - & 21,65 & 69,09 \\
FDA & - & 18,77 & 46,9 \\
Matéria Mineral & 6,61 & 6,96 & 7,29 \\
\hline
\end{tabular}

Diariamente registrou-se 0 consumo de concentrado, feno e sobras destes. $O$ peso vivo foi registrado semanalmente e o escore fecal três vezes por semana, utilizando-se uma escala de 1 a 3 , sendo escore 1 para fezes com consistência firme (normal), 2 para fezes de consistência mole, com perda do formato normal das fezes e 3 para fezes aquosas, indicando profusa diarreia, conforme descrito por Jones et al. (2004).

O delineamento experimental foi inteiramente casualizado, sendo os dados obtidos submetidos à análise de variância utilizando-se 0 pacote computacional SAS (SAS_INSTITUTE, 1999), sendo previamente testados para normalidade dos resíduos pelo Teste de Shapiro-Wilk, conforme descrito por Santana e Ranal (2004). O modelo matemático utilizado incluiu o efeito de tratamento e do peso inicial dos bezerros. Para a variável ganho de peso durante o período de aleitamento não foi observado normalidade dos resíduos, sendo os dados transformados para logaritmo de base 10 do ganho de peso diário em gramas. Os resultados foram apresentados com valores não transformados. As diferenças de tratamento com $\mathrm{P} \leq 0,05$ foram consideradas significativas e 0,05<P $\leq 0,10$ como tendência.

\section{RESULTADOS E DISCUSSÃO}

Os bezerros suplementados com probióticos apresentaram peso vivo mais elevado que o grupo controle ao final do experimento (Tabela 2), com tendência de maior peso vivo $(P=0,081)$ do grupo suplementado com probióticos em relação ao grupo controle no desaleitamento (6 $6^{\underline{a}}$ semana). $\mathrm{Na} 12^{\underline{a}}$ semana os bezerros recebendo probióticos foram $9,4 \mathrm{~kg}$ mais pesados $(P<0,05)$ que o grupo controle (Tabela 2). Resultado semelhante foi reportado por Lesmeister et al. (2004) e Galvão et al. (2005) ao avaliarem os efeitos de levedura no desempenho de bezerros. Entretanto, Batista et al. (2008) e Magalhães et al. (2008), ao avaliarem o uso de levedura no desempenho e sanidade de bezerros não encontraram diferença no peso vivo ao final do estudo. 
Houve tendência de maior GPD para o grupo recebendo probióticos nos dois períodos avaliados (aleitamento: $\mathrm{P}=0,067$ e após $\mathrm{O}$ desaleitamento: $\mathrm{P}=0,061$; Tabela 2). Porém, quando se considera 0 período total do experimento ( $1^{\underline{a}}$ a $12^{\underline{a}}$ semanas de vida) o GPD foi maior $(\mathrm{P}<0,05)$ para o grupo suplementado com probióticos $(0,677 \mathrm{~kg}$ $x \quad 0,566 \mathrm{~kg}$ do controle). O GPD do grupo suplementado com probióticos mostrou-se mais adequado para os padrões de crescimento esperados para a raça Holandesa $(0,800 \mathrm{~kg} / \mathrm{dia})$ em uma meta-análise conduzida por Zanton e Heinrichs (2005). Galvão et al. (2005) observaram maior GPD somente no período de aleitamento em bezerros, utilizando um suplemento probiótico contendo somente Saccharomyces cerevisiae. Lesmeister et al. (2004) relataram diferença no GPD nos períodos pós-aleitamento e total para bezerros recebendo cultura de levedura ( 1 e $2 \%$ do concentrado) em relação ao controle. Por outro lado, Gonçalves et al. (2000) concluíram que o uso de probióticos não influenciou o ganho de peso. Krehbiel et al. (2003), em revisão bibliográfica, relataram que em vários trabalhos os autores levantaram a hipótese de que o maior ganho de peso dos animais resultou da melhoria das condições do intestino devido ao escore fecal mais baixo (menos diarreia) em bezerros suplementados com probióticos.

\begin{tabular}{|c|c|c|c|c|c|}
\hline & \multicolumn{2}{|c|}{ Tratamentos } & \multirow{2}{*}{$\begin{array}{c}\text { Valor de } \\
\mathrm{P}\end{array}$} & \multirow{2}{*}{$\begin{array}{l}\mathrm{CV}^{\prime} \\
(\%)\end{array}$} & \multirow{2}{*}{$\mathrm{EPM}^{2}$} \\
\hline & Controle & Probiótion & & & \\
\hline \multicolumn{6}{|l|}{ Peso vivo, $\mathrm{kg}$} \\
\hline$\sigma^{2}$ semana & 54,53 & 58,82 & 0,081 & 11,04 & 1,618 \\
\hline 12 semana & 88,57 & 97,97 & 0,028 & 11,27 & 2,715 \\
\hline \multicolumn{6}{|l|}{ GPD', kg/dia } \\
\hline $1-6$ semanas & 0,332 & 0,421 & 0,067 & 7,23 & 0,054 \\
\hline $7-12$ & 0,801 & 0,931 & 0,061 & 19,87 & 0,044 \\
\hline \multicolumn{6}{|l|}{ semanas } \\
\hline $\begin{array}{c}1-12 \\
\text { semanas }\end{array}$ & 0,566 & 0,677 & 0,030 & $20,20 ?$ & 0,032 \\
\hline $\begin{array}{l}\text { CVV: coeficiente dev } \\
\text { "EPM: erro padrä́o } \\
\text { 3GPD: ganho de pes }\end{array}$ & . & & & & \\
\hline
\end{tabular}

A suplementação com probióticos não influenciou o consumo diário de concentrado (Tabela 3 ) em nenhum dos três períodos avaliados $(P>0,10)$, assim como de feno, o qual foi fornecido somente após o desaleitamento. $O$ fato da diferença para consumo após o desaleitamento $(0,196 \mathrm{~kg}$ a mais de concentrado para o grupo suplementado) não ser significativa pode ser atribuída ao elevado coeficiente de variação $(21,25 \%)$, o qual, no entanto, é compatível com os valores reportados por Kertz e ChesterJones (2004) que em uma revisão sobre 19 experimentos com bezerros e novilhas da raça Holandesa encontraram para consumo de concentrado por bezerros com idade média de 60 dias e CV médio de $32 \%$ (19 a 60\%). Batista et al. (2008) e Magalhães et al. (2008) também não encontraram diferença na ingestão de concentrado, enquanto Galvão et al. (2005) encontraram diferença somente no período de aleitamento e Lesmeister et al. (2004) observaram diferença nos períodos pós-aleitamento e total.

Consumo similar de alimentos (Tabela 3), com maiores ganhos de peso para os animais suplementados com probióticos (Tabela 2) resultaram em melhor conversão alimentar (kg alimento consumido em $\mathrm{MS} / \mathrm{kg}$ de ganho peso vivo) pela inclusão do probióticos na alimentação $(P<0,05)$ durante o período de aleitamento, com repercussão sobre a conversão alimentar no período total do experimento (Tabela 3). Além disto, a melhor conversão alimentar também pode estar relacionada à menor ocorrência de diarreia, representada pelo escore fecal mais baixo $(P<0,0001)$ nos bezerros em aleitamento, quando suplementados com probióticos (Tabela 4). Galvão et al. (2005) também relataram maior $\mathrm{CA}$ durante $\mathrm{O}$ aleitamento nos bezerros tratados com probióticos. Meyer et al. (2001) reportaram maior CA antes e após a 
desaleitamento, enquanto Lesmeister et al. (2004) não encontraram efeito sobre a CA.

\begin{tabular}{|c|c|c|c|c|c|}
\hline \multirow{2}{*}{ Variáveis } & \multicolumn{2}{|c|}{ Tratamentos } & \multirow{2}{*}{$\begin{array}{c}\text { Valor de } \\
\text { P }\end{array}$} & \multirow{2}{*}{$\begin{array}{l}\mathrm{CV}^{+} \\
(\%)\end{array}$} & \multirow{2}{*}{$E P^{2}$} \\
\hline & Controle & Probiótico & & & \\
\hline \multicolumn{6}{|l|}{ Concentrado, kg/dia } \\
\hline $1-6$ semanas & 0,453 & 0,444 & 0,915 & 47,17 & 0,054 \\
\hline $7-12$ semanas & 2,000 & 2,196 & 0,292 & 21,52 & 0,116 \\
\hline $1-12$ semanas & 1,216 & 1,322 & 0,405 & 24,46 & 0,080 \\
\hline \multicolumn{6}{|l|}{ Feno, kg/dia } \\
\hline 7- 12 & 0,500 & 0,549 & 0,289 & 21,51 & 0,029 \\
\hline \multicolumn{6}{|l|}{$\mathrm{CA}^{3}, \mathrm{~kg} \mathrm{MS} / \mathrm{kg}$ ganho } \\
\hline $1-6$ semanas & 3,083 & 2,163 & 0,017 & 35,67 & 0,242 \\
\hline $7-12$ semanas & 2,627 & 2,589 & 0,819 & 15,28 & 0,103 \\
\hline $1-12$ semanas & 2,898 & 2,374 & 0,019 & 19,04 & 0,129 \\
\hline
\end{tabular}

A redução do escore fecal pela suplementação com probióticos ocorreu somente no período de aleitamento. Entretanto, após o desaleitamento os quadros de diarreia foram raros, o que pode ser observado pela média do escore fecal próximo a um, indicando fezes com consistência normal em ambos os tratamentos (Tabela 4). Os resultados sugerem que a adição de probióticos a dieta pode modificar 0 estado microbiano no intestino dos bezerros e diminuir a ocorrência de diarreia. Krehbiel et al. (2003) relataram que os probióticos podem competir com patógenos por sítios de aderência na superfície intestinal. Nos estudos de Galvão et al. (2005), Batista et al. (2008) e Magalhães et al. (2008) o uso de levedura diminui o risco de diarreia, mas não houve efeito sobre o escore fecal.

\begin{tabular}{|c|c|c|c|c|c|}
\hline \multirow{2}{*}{ Variáveis } & \multicolumn{2}{|c|}{ Tratamentos } & \multirow{2}{*}{$\begin{array}{c}\text { Valor de } \\
\mathrm{P}\end{array}$} & \multirow{2}{*}{$\begin{array}{l}\mathrm{CV}^{4} \\
(\%)\end{array}$} & \multirow{2}{*}{$E^{2} M^{2}$} \\
\hline & Controle & Probiótico & & & \\
\hline \multicolumn{6}{|l|}{ Escore fecal $^{3}$} \\
\hline $1-6$ semanas & 1,389 & 1,064 & $<0,0001$ & 13,35 & 0,042 \\
\hline $7-12$ semanas & 1,050 & 1,018 & 0,241 & 6,62 & 0,017 \\
\hline
\end{tabular}

\section{CONCLUSÃO}

A suplementação de bezerros com probióticos resultou em diminuição do escore fecal durante o período de aleitamento, proporcionando ganho de peso mais elevado e melhor conversão alimentar no período experimental ( $1^{\mathrm{a}}$ a $12^{\mathrm{a}}$ semanas). Portanto, probióticos constituídos por Saccharomyces cerevisae, cepa KA500 e Pediococcus acidilactici, cepa KA25 são uma alternativa para melhorar o desempenho de bezerros durante 0 aleitamento resultando em maior peso vivo na $12^{\mathrm{a}}$ semana de vida. Mais estudos são necessários para avaliar os efeitos da suplementação dos probióticos sobre o peso vivo e idade ao primeiro parto e desempenho na primeira lactação.

\section{AGRADECIMENTOS}

Os autores agradecem à Kera Nutrição Animal (Bento Gonçalves $\mathrm{RS}$ ), por oferecer o suporte necessário à realização desta pesquisa.

\section{REFERÊNCIAS}

BATISTA, C.G; COELHO, S.G; RABELO, E. et al. Desempenho e saúde de bezerras alimentadas com leite sem resíduo de drogas antimicrobianas ou leite de vacas tratadas contra mastite adicionado ou não de probióticos. Arquivo Brasileiro de Medecina Veterinária e Zootecnia, v.60, n.1, p.185-191, 2008.

COPPOLA, M. M.; TURNES, C. G Probióticos e a resposta imune. Ciência Rural, Santa Maria, v.34, n.4, p.1297-1303, 2004.

FILHO-LIMA, J.V.; VIEIRA, E.C.; NICOLI, J.R. Antagonistic effect of Lactobacillus acidophilus, Saccharomyces boulardii and Escherichia coli combinations against experimental infections with Shigella flexneri and Salmonella enteritidis subsp. typhimurium in gnotobiotic mice. Journal of Applied Microbiology, v.88, p.365-370, 2000.

FULLER, R. Probiotic in man and animals - a review. Journal Applied Bacteriology, Malden, v.66, p.365-378, 1989.

GALVÃO, K. N., SANTOS, J. E., COSCIONI, A. et al. Effect of feeding live yeast products to calves with failure of passive transfer on performance and patterns of antibiotic resistance in fecal Escherichia coli. Reproduction, 
Desempenho de bezerros da raça Holandesa suplementados com probiótico a base de saccharomyces cerevisae, cepa ka500 e pediococcus acidilactici

Nutrition, Development, v.45, n.4, p.427-440. 2005.

GARCIA, G R. Caracterização microbiológica e avaliação de uma cepa de Bacillus subtilis no desempenho de bezerros da raça holandesa. 2008. 68f. Tese (Doutorado em Microbiologia Agropecuária) - Faculdade de Ciências Agrárias e Veterinária - Universidade Estadual Paulista Julio de Mesquita, Jaboticabal.

GONÇALVES, G.D.; SANTOS, G.T.; RIGOLON, L.P. et al. Efeito da adição de probióticos na dieta, sobre o estado sanitário e desempenho de bezerros da raça Holandesa. Brazilian Journal of Veterinary Research and Animal Science, v.37, n.1, p.74-78, 2000.

JENSEN, G. S.; PATTERSON, K. M.; YOON, I. Nutritional yeast culture has specific antimicrobial properties without affecting healthy flora - Preliminary results. Journal of Animal and Feed Sciences, v.17, p.247-252, 2008.

JONES, C. M.; JAMES, R. E.; QUIGLEY, J. D. et al. Influence of pooled colostrum or colostrum replacement on $\lg G$ and evaluation of animal plasma in milk replacer. Journal of Dairy

Science, v.87, n.6, p.1806-14. 2004.

KAWAKAMI, S. I.; YAMADA, T.; NAKANICHI, N. et al. Feeding of lactic acid bacteria and yeast on growth and diarrhea of Holstein calves. Journal of Animal and Veterinary Advances., v.9, n.7, p.1112-1114, 2010.

KERTZ, A.F.; CHESTER-JONES, H. Guidelines for measuring and reporting calf and heifer experimental data. Journal of Dairy Science. v.87, n.11, p.3577-3580, 2004.

KREHBIEL, C. R.; RUST, S. R.; ZHANG, G et al. Bacterial direct-fed microbials in ruminant diets: Performance response and mode of action.

Journal of Animal Science, v.81, (Suplemento especial 2), p.120-132, 2003.

LESMEISTER, K. E., HEINRICHS, A. J. ,GABLER, M. T. Effects of supplemental yeast (Saccharomyces cerevisiae) culture on rumen development, growth characteristics, and blood parameters in neonatal dairy calves. Journal of Dairy Science, v.87, n.6, p.1832-9, 2004.
MAGALHÃES, V. J. A., SUSCA, F., LIMA, F. S. et al. Effect of feeding yeast culture on performance, health, and immunocompetence of dairy calves. Journal of Dairy Science, v.91, n.4, p.1497-509, 2008.

MAPA, Ministério da Agricultura, Pecuária e Abastecimento. Instrução Normativa № 13, de 30 de novembro de 2004. Disponível em: <http://extranet.agricultura.gov.br/sislegis/action/ detalhaAto.do?method=consultarLegislacao Federal>. Acesso em: 04/10/2013.

MARTIN, S. A.; NISBET, D. J. Effect of directfed microbials on rumen microbial fermentation. Journal of Dairy Science, v.75, n.6, p.1736$1744,1992$.

PEREIRA, V. V., BENEDETTI, E., GUIMARÃES, L. K. P. et al. Probióticos no desempenho e estado sanitário de bezerros leiteiros. In: $45^{\text {a }}$ REUNIÃO ANUAL DA SOCIEDADE BRASILEIRA DE ZOOTECNIA. ZOOTECNIA, 2008. Lavras. Anais.... Lavras : Editora Universitária da UFLA, 2008. v. CD-Rom.

RODRIGUEZ-PALACIOS, A.; STAEMPFLI, $\mathrm{H}$. R.; DUFFIELD, T. et al. Isolation of bovine intestinal Lactobacillus plantarum and Pediococcus acidilactici with inhibitory activity against Escherichia coli O157 and F5. Journal Applied Microbiology. v.106, n.2, p.393-401. 2009.

SANTANA, D. G ,RANAL, M. A. Análise estatística. In: FERREIRA, A. G,F., B. (Ed.). Germinação - do básico ao aplicado. Porto Alegre ArtMed. Análise estatística, p.197-208, 2004.

SAS_INSTITUTE. SAS/STAT User's Guide 8.0. Cary-NC: SAS Institute. 1999.

TIMMERMAN, H.M.; MULDER, L.; EVERST, H. et al. Health and grow of veal calves fed milk replacers with or without probiotics. Journal of Dairy Science, v.88, n.6, p.2154 - 2165, 2005.

ZANTON, G I.; HEINRICHS, A. J. Meta-analysis to assess effect of prepubertal average daily gain of holstein heifers on first-lactation production. Journal of Dairy Science. v.88, n.11, p.3860-3867, 2005. 